\title{
Skeletonizing en-bloc gastrectomy for adenocarcinoma in Caucasian patients
}

\author{
Jean-Marie Collard, Jacques Malaise, Jean-Yves Mabrut, and Paul-Jacques Kestens \\ Upper G-I Surgery Unit, Louvain Medical School, Brussels, Belgium
}

\begin{abstract}
Background. The prognostic relevance of a Japanese-like lymphadenectomy for gastric adenocarcinoma in Caucasian patients is not well established.

Methods. Skeletonizing en-bloc gastrectomy (SEBG) (including removal of the stomach, excision of the potentially involved lymph nodes, and skeletonization of the main anatomic structures in the upper abdominal floor) was attempted in 216 consecutive patients with adenocarcinoma of the stomach. Gastrectomy was total in 143 patients, and subtotal in 72. One debilitated patient had a wedge resection of the gastric wall.

Results. SEBG was performed in 160 patients $(74 \%)$, whereas 56 patients $(26 \%)$ had a palliative gastrectomy (PG) without lymph node dissection. The feasibility rate of SEBG was influenced significantly $(P<0.001)$ by the depth of wall penetration, so that it dropped from $97 \%$ in $\mathrm{T} 1$ tumors to $91 \%$, $65 \%$, and $17 \%$ in those classified T2, T3, and T4, respectively. The 5-year survival rate, including postoperative mortality $(0.9 \%)$ was $48 \%$ for the whole series, $66 \%$ after SEBG, and $0 \%$ after PG. The 5-year survival rate after SEBG was related significantly to the lymph node involvement (N0, 75\% vs $\mathrm{N}+$, $54 \% ; P=0.008)$ and to its magnitude $(\mathrm{N}+,<5$ metastatic lymph nodes, $62 \%$ versus $\mathrm{N}+, \geq 5$ metastatic lymph nodes, $39 \% ; P=0.018)$. Considering the fact that 9 patients died of an unrelated cause before the postoperative term of 5 years, the cancer-related survival rate 5 years after SEBG was $71 \%$ in the whole group of 160 patients. This survival rate was $82 \%$ in patients with normal lymph nodes, versus $56 \%$ in those with metastatic nodes $(P<0.001)$.

Conclusion. SEBG was feasible in three-quarters of a population of Caucasian patients operated on for gastric adenocarcinoma. SEBG provided a chance for a longterm favorable outcome in three-quarters of patients with normal lymph nodes and in more than half of those with metastatic lymph nodes. These results are similar to those achieved
\end{abstract}

Offprint requests to: J.-M. Collard, Upper G-I Surgery Unit, St-Luc Academic Hospital, Hippocrate Avenue 10, B 1200, Brussels, Belgium

Received: November 15, 2002 / Accepted: July 17, 2003 after radical gastrectomy in Japanese patients with gastric adenocarcinoma.

Key words Gastrectomy $\cdot$ Carcinoma $\cdot$ Stomach

\section{Introduction}

Over the past few decades, two different surgical attitudes were adopted towards adenocarcinoma of the stomach. On one hand, Far Eastern surgeons, especially those from Japan [1-3] developed techniques of gastrectomy that included extended lymph node clearance of the upper abdominal floor. On the other hand, with the exception of some leading centers [4-8], most Western surgical teams restricted gastric resection to the removal of the stomach itself with some of the immediately adjacent lymph nodes [9-12]. As a consequence, longterm survival rates achieved by Asian surgeons were usually much higher than those reported by their Western colleagues [13]. Moreover, Western surgeons were discouraged from performing more radical gastric resections in a routine setting by the results of four randomized trials that failed to demonstrate any superiority, in terms of overall longterm survival, of gastrectomy with extended lymph node dissection over a more limited surgical procedure [14-17]. In addition to its inability to yield high survival rates, the so-called Japanese technique in these trials revealed a higher postoperative morbidity in comparison to gastrectomy with limited lymph node clearance. This was ascribed to the addition of a pancreatic resection to gastrectomy in three of these four trials [14-16] and to the existence of less favorable anatomic conditions in Caucasians than in Asians [18]. Actually, the two largest comparative studies $[14,15]$ were conducted in a large number of surgical centers where not all the contributing surgeons had a large experience of radical surgery for upper gastro-intestinal (G-I) cancer at the time of the trials. 
The concept of resection of the organ in which a neoplastic process takes origin en-bloc with potentially invaded lymph nodes and soft tissues was introduced by Logan 40 years ago to treat cancers of the esophagus and cardia [19]. Over time, this technique, which results in a real skeletonization of the operative field as seen in textbooks of anatomy, was revealed to provide esophageal cancer patients with a higher chance for a longterm favorable outcome than that offered by simple esophageal resection $[20,21]$.

In this setting, it was interesting to see if the application of the en-bloc concept (skeletonizing enbloc gastrectomy; SEBG) to Caucasian patients with adenocarcinoma of the stomach by a surgical team having a large experience of radical esophageal resection for cancer [20,22] could yield survival rates similar to those achieved by Japanese surgeons after extended lymph node clearance of the upper abdominal floor.

\section{Patients and methods}

\section{Patients}

Over a 17-year period, from 1984 to 2001, 251 consecutive patients underwent a gastrectomy for neoplastic disease of the stomach at the Academic Hospital of the Université Catholique de Louvain (UCL). Of these 251 patients, 216 (125men and 91 women, aged 21 to 88 years [mean, 63.4 years]) had an adenocarcinoma. Seventy-four patients (34\%) were aged 70 years or more. From a clinical standpoint, the 216 patients were classified into three categories according to the clinical classification of the American Society of Anesthesiologists (ASA) [23]: ASA $1(n=42)$, ASA $2(n=113)$, and ASA $3(n=61)$. From a macroscopic standpoint, the tumor was centered on the upper, middle, and lower part of the stomach in 18, 57, and 131 patients, respectively. Ten patients had an adenocarcinoma that had developed in the gastric stump of a previous distal gastrectomy. From a histologic standpoint, 200 tumors were undoubtedly classified according to Lauren [24] into intestinal $(n=124)$, or diffuse $(n=76)$ types. It was difficult for our pathologists to classify the 16 remaining tumors into either of the Lauren's histologic types with certainty because of poor differentiation of the lesion.

\section{Surgical technique}

The basic principle of the surgical technique was the removal of the stomach en-bloc with the potentially invaded locoregional lymph nodes and soft tissues, so that a single block of tissue was given to the pathologist and immediately immersed in formalin. As far as macroscopically complete resection of the neoplastic process was feasible, dissection was carried out flush with the wall of the anatomic structures in the vicinity of the stomach rather than close to the gastric wall itself. At this point, the vascular pedicles to the stomach were ligated and divided at their origin. All lymph nodes and soft tissues in the hepatoduodenal ligament, and along the celiac axis, the common hepatic artery, the splenic artery and vein at the upper border of the pancreas, the left aspect of the portal vein, the anterior aspect of the inferior vena cava, and the anterior aspect of the left adrenal gland were removed en bloc. Dissection of the tail of the pancreas sometimes required removal of the splenic artery [25]. Lymph node clearance of the left side of the upper abdominal floor included splenectomy (or not). The transverse colon or mesocolon, or the tail of the pancreas, were included in the block whenever they were invaded by the neoplastic process. As a consequence, all the anatomic structures in the upper abdominal floor were skeletonized, so that at the end of the procedure the surgical field resembled that seen in anatomic plates.

In contrast, dissection was performed close to the gastric wall without any attempt to remove locoregional lymph nodes, as soon as it was obvious that a macroscopically complete resection was not feasible, and in some debilitated patients operated on with a palliative intent.

In practice, gastrectomy was total in 143 patients $(66 \%)$, whereas it was subtotal in $72(33 \%)$. One patient with very poor general condition had a wedge resection of the gastric wall only. The percentage of total gastrectomies decreased from the group of patients with a tumor arising in the gastric stump of a previous distal gastrectomy $(10 / 10 ; 100 \%)$ or those with an upper-third tumor $(18 / 18 ; 100 \%)$ to those with a middle-third tumor $(49 / 57 ; 86 \%)$, and those with a lower-third tumor (66/ $131 ; 50 \%)$. Splenectomy was performed in 90 patients $(42 \%)$, and the transverse colon or mesocolon, the tail of the pancreas, and a diaphragmatic patch were removed in 4,9 , and 1 patients, respectively.

After total gastrectomy, digestive continuity was restored, using either a 60-cm Roux-en-Y jejunal loop [26] $(n=85)$ or a $60-\mathrm{cm}$ jejunal loop interposed between the esophagus and duodenum $(n=58)$. After subtotal gastrectomy, the upper G-I tract was reconstructed using one of three procedures, B1 gastroduodenostomy $(n=$ $20)$, B2 gastrojejunostomy $(n=43)$, or gastrojejunostomy according to the Holt technique (Holt and Large [27]) $(n=9)$. Esophagojejunal anastomoses were performed using either a single-layer running-suture technique $(n=110)$ or a circular stapling device $(n=33)$. In the same way, duodenojejunostomy was either handsewn $(n=34)$ or stapled $(n=24)$. All the other anastomoses were hand-sewn. All the operations were done by or under the direct supervision of either of the two senior authors (J.M.C. or P.J.K.). 


\section{Data analysis}

Data relating to the feasibility of SEBG were analyzed according to tumor location in the stomach; histologic type at postoperative microscopic examination of the specimen; depth of wall penetration based on the $\mathrm{T}$ factor, and patient sex, age ( $<70$ or $\geq 70$ years), and clinical stage in the ASA classification. Two-tailed $\chi^{2}$ or Fisher exact tests were used for comparison of categoric variables with a $P$ value of less than 0.05 .

Patients who underwent surgery more than 5 years previously were followed either until the date of death or for at least the 5 years after surgery, whereas the more recent patients were followed until either the date of death or January 2002 . Only one patient $(0.4 \%)$ was lost to follow-up. Five-year survival rates were calculated according to radicality of the operation (SEBG versus PG); patient sex, age, and stage in the ASA classification; tumor location in the stomach; histologic type at microscopic examination of the resected specimen; extent of the gastrectomy (total versus subtotal); performance of a splenectomy or not; and $\mathrm{T}$ and $\mathrm{N}$ factors. Neoplastic processes that were resected in totality in spite of the presence of metastatic lymph nodes in the resected specimen were subclassified further depending on whether fewer than five or five or more of the resected lymph nodes were invaded. This subclassification allowed a comparison of the survival rates achieved in the present series of gastric adenocarcinoma patients with the previously published survival rates in our patients operated on for esophageal adenocarcinoma [20,22]. Survival curves were established according to the Kaplan-Meier method and compared using the log rank or Cox F-tests, with a $P$ value of less than 0.05. The Cox proportional hazard test was used for multivariate analysis.

\section{Results}

\section{Feasibility of SEBG}

SEBG was performed in 160 patients (74\%), whereas 56 patients $(26 \%)$ had a palliative gastrectomy (PG), because the neoplastic process could not be removed in totality from a macroscopic standpoint $(n=48)$ or because the existence of a poor general status precluded extended surgical dissection $(n=8)$. The prevalence of so-called early carcinoma (T1N0) among the 160 patients undergoing SEBG was $32.5 \%$. The prevalence of neoplastic processes with metastatic lymph nodes in these 160 patients increased from $13 \%$ in T1 tumors to $48 \%, 62 \%$, and $100 \%$ in those classified as T2, T3, and T4, respectively $(P<0.001)$.

As shown in Table 1, the feasibility rate did not differ significantly according to patient sex; tumor location in
Table 1. Feasibility of skeletonizing en-bloc gastrectomy (SEBG)

\begin{tabular}{lrr}
\hline Parameters & $\begin{array}{r}\text { Ratio of SEBG } \\
\text { to all resections }\end{array}$ & $P$ value \\
\hline Male & $91 / 125(73 \%)$ & 0.731 \\
Female & $69 / 91(76 \%)$ & \\
Age $<70$ years & $115 / 142(81 \%)$ & 0.002 \\
Age $\geq 70$ years & $45 / 74(61 \%)$ & \\
ASA 1-2 & $121 / 155(78 \%)$ & 0.050 \\
ASA 3 & $39 / 61(64 \%)$ & \\
Upper third & $16 / 18(89 \%)$ & 0.489 \\
Middle third & $41 / 57(72 \%)$ & \\
Lower third & $96 / 131(73 \%)$ & \\
Gastric stump & $6 / 10(60 \%)$ & 0.076 \\
Intestinal & $86 / 124(69 \%)$ & \\
Diffuse & $59 / 76(78 \%)$ & \\
Poorly differentiated & $15 / 16(94 \%)$ & \\
T1 & $60 / 62(97 \%)$ & \\
T2 & $21 / 23(91 \%)$ & \\
T3 & $77 / 119(65 \%)$ & \\
T4 & $2 / 12(17 \%)$ & \\
\hline ASA Ama &
\end{tabular}

ASA, American Society of Anesthesiologists

the stomach; and histologic type. In contrast, the feasibility rate was influenced significantly by patient age $(P$ $=0.002)$ and ASA stage $(P=0.05)$, and above all, by the depth of wall penetration $(P<0.001)$, so that it dropped from $97 \%$ in $\mathrm{T} 1$ tumors to $91 \%, 65 \%$, and $17 \%$ in those classified as $\mathrm{T} 2, \mathrm{~T} 3$, and $\mathrm{T} 4$, respectively.

\section{Postoperative outcome}

Two patients $(0.9 \%)$ died during the postoperative inhospital stay, one of Addisonian shock and the other of sepsis secondary to anastomotic leakage. Sixty-seven complications developed in 56 patients (26\%) (Table 2). A pancreatic fistula occurred in 24 patients, and all these were treated by simple drainage and IV administration of Somatostatin (UCB, Braines, Belgium). An anastomotic fistula occurred in 6 of the 143 patients (4\%) with an esophagojejunal anastomosis.

\section{Survival}

The 5-year survival rate, including the two postoperative deaths, was $48 \%$ for the whole series of 216 patients, $66 \%$ for the 160 patients who underwent SEBG, and $0 \%$ for the 56 patients operated on with a palliative intent (Fig. 1).

Considering the 160 patients operated on using the SEBG technique, univariate analysis indicated (Table 3 ) that the 5-year survival was not significantly affected by patient sex, age $(\geq 70$ or $<70)$, and ASA stage; tumor location in the gastric pouch; histologic type; the type of gastrectomy (total vs subtotal); and performance of a splenectomy or not. In contrast, the 5-year survival rate 
Table 2. Postoperative complications in the 216 patients studied

Esophagojejunal anastomosis fistula

Duodenal stump fistula

Esophagojejunal stenosis

Pancreatic fistula

Intraperitoneal bleeding

Bowel obstruction

Subhepatic abcess

Intrahepatic abcess

Cholecystitis

Hemothorax

Parietal abcess

Catheter-related septicemia

Pulmonary infection

Leg phlebitis

Pulmonary embolism

Esophageal varices rupture

Cerebral vascular accident

Addisonian shock

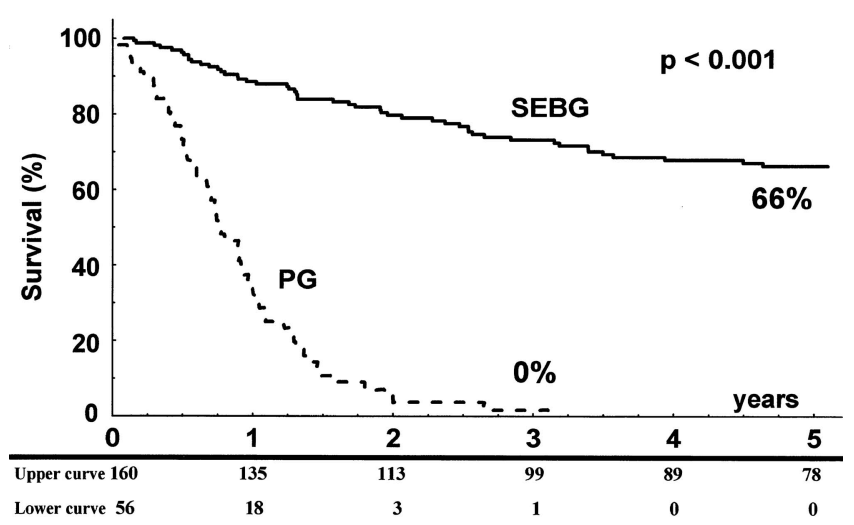

Fig. 1. Kaplan-Meier survival in the 160 patients who underwent skeletonizing en-bloc gastrectomy ( $S E B G$; upper curve) and in the 56 patients operated on with a palliative intent (palliative gastrectomy $[P G]$; lower curve). The number of subjects at risk in each interval is shown at the bottom of the graph

was significantly higher $(P=0.008)$ in patients with normal lymph nodes $(75 \%)$ than in those with metastatic nodes (54\%). In addition (Fig. 2), the 5-year survival rate in patients with fewer than five metastatic lymph nodes in the resected specimen $(62 \%)$ did not significantly differ $(P=0.246)$ from that in nodenegative patients $(75 \%)$, but survival in the former subgroup $(62 \%)$ was significantly higher $(P=0.018)$ than that in the subgroup of patients with five or more metastatic lymph nodes (39\%). Likewise, the 5-year survival dropped significantly $(P<0.001)$ according to the $\mathrm{T}$ factor (T1, $86 \%$ vs $\mathrm{T} 2,62 \%$ vs $\mathrm{T} 3,48 \%$ ). However, multivariate analysis indicated that lymph node involvement ( $\mathrm{N} 0$ vs $\mathrm{N}+$ ) and its magnitude $(\mathrm{N} 0$ vs $\mathrm{N}+$,

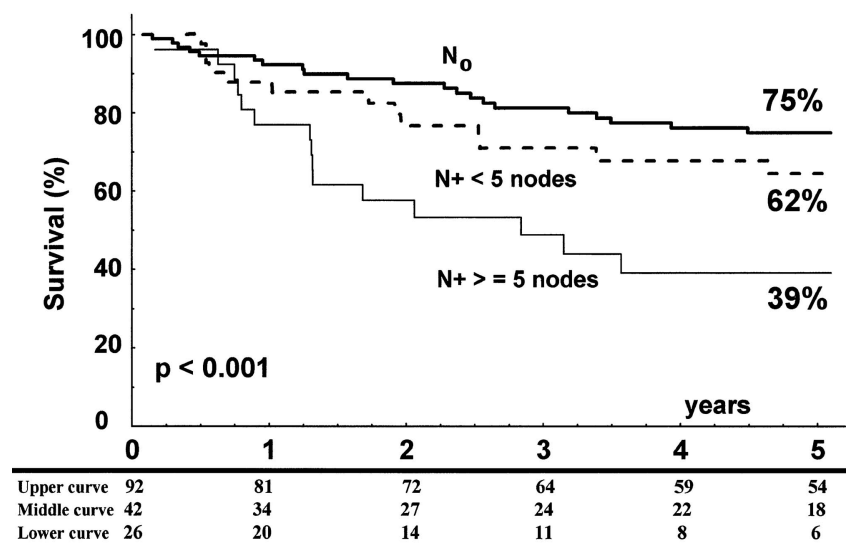

Fig. 2. Kaplan-Meier survival according to lymph node involvement and its magnitude (upper curve, 92 patients with normal lymph nodes; middle curve, 42 patients with fewer than five metastatic lymph nodes; lower curve, 26 patients with five or more 5 metastatic lymph nodes). The number of subjects at risk in each interval is shown at the bottom of the graph

$<5$ nodes vs $\mathrm{N}+, \geq 5$ nodes) were the only factors to influence long-term survival significantly $(P=0.018$ and $P=0.002$, respectively).

Nine patients 7 classified as N0 $(7 / 92 ; 8 \%)$ and 2 classified as $\mathrm{N}+(2 / 68 ; 3 \%)$ died of an unrelated cause within the 5 years following SEBG. Consequently, the cancer-related survival 5 years after SEBG was $71 \%$ for the whole group of 160 patients, and it was $82 \%$ for patients with normal lymph nodes versus $56 \%$ for those with metastatic lymph nodes $(P<0.001)$.

\section{Discussion}

Patients with an adenocarcinoma of the stomach belong to two distinct categories. On the one hand, about onequarter of patients seek consultation at a time when the neoplastic process has already spread beyond the limits of resection or their general status is so poor that the only reasonable treatment consists of removal of the organ containing the primary lesion. For want of providing longterm survival and cure, palliative gastrectomy is a valuable therapeutic tool that allows restoration of a free passage for feeding, or for anticipation of upper G-I obstruction or bleeding. On the other hand, about three-quarters of patients fullfil intraoperative conditions for a radical surgical procedure that aims to eradicate the underlying neoplastic disease [28]. In this respect, the present study shows that SEBG can be performed irrespective of the histologic type of the primary and of its location in the stomach, with the feasibility rate depending mainly on the depth of wall penetration. The lower feasibility rate in elderly patients and in those in stage 3 of the ASA classification 
Table 3. Five-year survival rates after SEBG

\begin{tabular}{|c|c|c|c|c|}
\hline Parameters & $n$ & $\begin{array}{c}\text { 5-Year survival } \\
\text { rate }\end{array}$ & $\begin{array}{c}P \text { value } \\
\text { (univariate) }\end{array}$ & $\begin{array}{c}P \text { value } \\
\text { (multivariate) }\end{array}$ \\
\hline Male & 91 & $64 \%$ & 0.476 & - \\
\hline Female & 69 & $69 \%$ & & \\
\hline Age $<70$ years & 115 & $68 \%$ & 0.412 & - \\
\hline Age $\geq 70$ years & 45 & $62 \%$ & & \\
\hline ASA $1-2$ & 121 & $69 \%$ & 0.083 & - \\
\hline ASA 3 & 39 & $56 \%$ & & \\
\hline Upper third & 16 & $62 \%$ & 0.794 & - \\
\hline Middle third & 41 & $64 \%$ & & \\
\hline Lower third & 96 & $68 \%$ & & \\
\hline Gastric stump & 6 & $42 \%$ & & \\
\hline Intestinal & 86 & $69 \%$ & 0.178 & - \\
\hline Diffuse & 59 & $67 \%$ & & \\
\hline Poorly differentiated & 15 & $33 \%$ & & \\
\hline $\mathrm{T} 1$ & 60 & $86 \%$ & $<0.001$ & $0.204 * *$ \\
\hline $\mathrm{T} 2$ & 21 & $62 \%$ & & $0.168 *$ \\
\hline $\mathrm{T} 3$ & 77 & $48 \%$ & & \\
\hline $\mathrm{T} 4$ & 2 & - & & \\
\hline N0 & 92 & $75 \%$ & 0.008 & $0.018^{*}$ \\
\hline $\mathrm{N}+$ & 68 & $54 \%$ & & \\
\hline N0 & 92 & $75 \%$ & 0.002 & $0.002 * *$ \\
\hline $\mathrm{N}+(<5$ nodes $)$ & 42 & $62 \%$ & & \\
\hline $\mathrm{N}+(\geq 5$ nodes $)$ & 26 & $39 \%$ & & \\
\hline Splenectomy & 83 & $67 \%$ & 0.763 & - \\
\hline No splenectomy & 77 & $65 \%$ & & \\
\hline Total gastrectomy & 58 & $68 \%$ & 0.667 & - \\
\hline $\begin{array}{l}\text { Subtotal gastrectomy } \\
\text { (lower third) }\end{array}$ & 38 & $68 \%$ & & \\
\hline
\end{tabular}

shows that many delibitated, elderly people seek consultation late in the course of the neoplastic process.

Resection of the stomach en bloc with potentially invaded locoregional lymph nodes provides two-thirds of those patients with a chance of a longterm survival. The longterm outcome after skeletonization of the main anatomic structures in the upper abdomen is closely related to both the lymph node involvement and its magnitude [4]. Indeed, the 5-year survival rate in the current series dropped from $75 \%$ in the presence of a neoplastic process limited to the gastric wall to $62 \%$ in the presence of fewer than five metastatic lymph nodes and to $39 \%$ when this number was equal to or greater than five. The fact that the difference in survival between patients with no lymph node involved and those with fewer than five metastatic lymph nodes did not reach statistical significance indicates that SEBG is a technique that enables the surgeon to circumbscribe a large proportion of those neoplastic processes with a limited extragastric component [29,30]. These figures are quite similar to those reported by our Japanese colleagues after gastrectomy with very extended lymph node clearance of the upper abdomen [1-3,13]. For instance, comparison of the current series of Caucasian patients with the large series of 1475 patients treated at the National Cancer-Center, Tokyo [28] indicates (Fig. 3) that the 5-year survival in both series is quite similar in patients with metastatic lymph nodes and in those with a transmural tumor. The trend for a slightly worse prognosis in Caucasian patients with N0 disease probably highlights the higher prevalence of early cancer (T1N0) in the Japanese series and the fact that $8 \%$ of our patients with normal lymph nodes died of an unrelated cause before the term of 5 years after the operation, so that the raw survival rate of $75 \%$ after 5 years reflected in fact, a cancer-related survival rate of $82 \%$.

The achievement in Caucasian patients of survival rates similar to those obtained in Japanese patients lies in the application of the principles of surgical dissection used by our Far Eastern colleagues for years [1]. Skeletonizing en-bloc gastrectomy (SEBG) requires meticulous histologic dissection, great care to handle the anatomic structures in the operative field, and awareness from the surgeon so that the prognosis of the disease is related strictly to both the quality and completeness of the surgical dissection. However, such a histologic dissection may be more difficult in some Cau- 

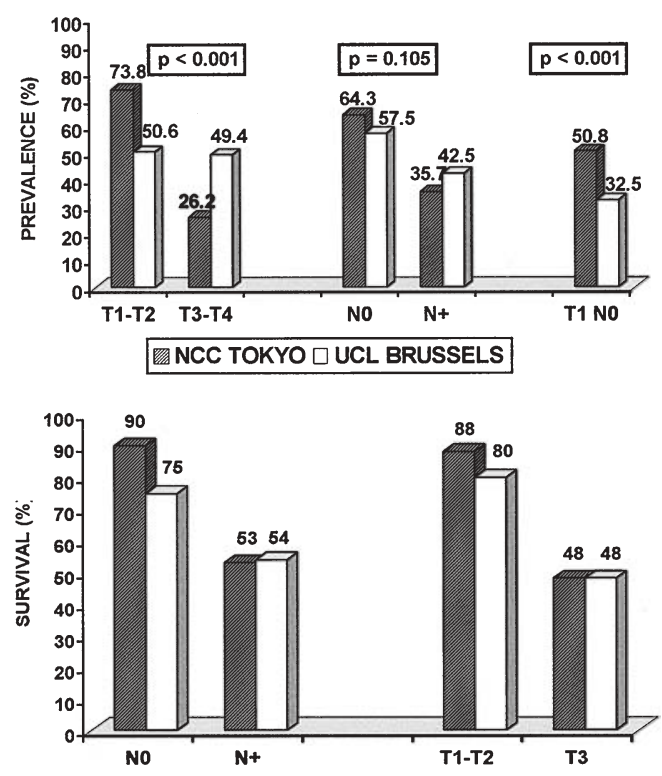

Fig. 3. Tumor characteristics (top) and 5-year survival rates (bottom) in a series of 1475 patients from the National Cancer Center (NCC), Tokyo (dashed bars) and in the 160 patients from the Université Catholique de Louvain (UCL), Brussels (blank bars) operated on for gastric adenocarcinoma with a curative intent

casians than in most Asians, because of the existence of less favorable anatomic conditions in the former patients than in the latter [18,31]. Another explanation for the encouraging results in our series might be that all the operations were performed by or under the direct supervision of senior surgeons having a large experience of skeletonizing en-bloc esophagectomy for cancer $[20,22]$.

In this regard, there is a big difference between patients undergoing an en-bloc resection for gastric cancer and those having an operation based on the same principles for an adenocarcinoma of the esophagus or cardia. Indeed, unlike the very few esophageal cancer patients ( $7 \%$ in our own series [22]), almost $40 \%$ of our current patients who underwent a skeletonizing en-bloc resection for a gastric cancer and who had five or more metastatic lymph nodes could anticipate long-term survival. This observation indicates that local control of the neoplastic disease is much easier for a gastric adenocarcinoma that invades only the upper abdominal lymph nodes [30] than for an esophageal adenocarcinoma that spreads into cervical, thoracic, and abdominal lymph nodes [32].

Although $28 \%$ of our patients were in stage 3 of the ASA classification, very radical surgery for gastric cancer could be done with negligible postoperative mortality and acceptable morbidity. This observation confirms data from other Western surgical teams $[4,7,18]$ and does not support the concept of performing nonradical operations for the sole purpose of minimizing postoperative morbidity and mortality [8]. The use of a computer program, such as the one developed by Maruyama and colleagues (Bollschweiler et al. [33]) from the analysis of more than 3000 resected specimens, allows reliable preoperative estimation of the lymph node involvement and restriction of the lymph node dissection to the potentially invaded stations rather than skeletonizing all the anatomic structures in the upper abdomen blindly. Selective dissection should be particularly valuable in debilitated patients who are at low risk for having metastatic lymph nodes along the splenic vessels so that the morbidity linked to the dissection of the tail of the pancreas can be avoided [26, 34]. On the other hand, considering the fact that the longterm prognosis of antral adenocarcinomas did not depend on the upward extent of the gastric resection [10], and that almost all anastomotic fistulas occurred at the level of the esophago-jejunal anastomosis after total gastrectomy, subtotal gastrectomy with maintenance of a gastric cuff [35] is a relevant procedure in patients with an antral lesion.

In conclusion, SEBG performed by experienced surgeons in Caucasian patients with gastric adenocarcinoma can yield survival rates similar to those reported by leading Japanese surgical teams. However, the fact that about half the patients operated on for a gastric adenocarcinoma and one-third of those who underwent a potentially curative gastrectomy died within the 5 years following the operation, despite an agressive surgical approach, stresses the need for establishing effective adjuvant treatments after this type of surgery. The recent publication of encouraging data after nonradical gastrectomy plus radio-chemotherapy in American patients [9] should incite leading surgical teams to start prospective trials based on the SEBG technique.

\section{References}

1. Maruyama K, Sasako M, Kinoshita T, Sano T, Katai H. Surgical treatment for gastric cancer: the Japanese approach. Semin Oncol 1996;23:360-8.

2. Kodama Y. Evaluation of extensive lymph node dissection for carcinoma of the stomach. World J Surg 1981;5:241-8.

3. Noguchi Y, Imada T, Matsumoto A, Coit DG, Brennan MF. Radical surgery for gastric cancer. A review of the Japanese experience. Cancer 1989;64:2053-62.

4. Mendes de Almeida JC, Bettencourt A, Santos Costa CS, Mendes de Almeida JM. Curative surgery for gastric cancer: study of 166 consecutive patients. World J Surg 1994;18:889-94.

5. Siewert JR, Böttcher K, Roder JD, Busch R, Hermanek P, Meyer $\mathrm{HJ}$, et al. Prognostic relevance of systematic lymph node dissection in gastric carcinoma. Br J Surg 1993;80:1015-8.

6. Griffith JP, Sue-Ling HM, Martin I, Dixon MF, McMahon MJ, Axon ATR, et al. Preservation of the spleen improves survival after radical surgery for gastric cancer. Gut 1995;36:684-90. 
7. Jatzko GR, Lisborg PH, Denk H, Klimpfinger M, Stettner HM. A 10-year experience with Japanese-type radical lymph node dissection for gastric cancer outside of Japan. Cancer 1995;76:1302-12.

8. Pacelli F, Doglietto GB, Bellantone R, Alfieri S, Sgadari A, Crucitti F. Extensive versus limited lymph node dissection for gastric cancer: a comparative study of 320 patients. Br J Surg 1993;80:1153-6.

9. MacDonald JS, Smalley SR, Benedetti J, Hundahl SA, Estes NC, Stemmermann GN, et al. Chemoradiotherapy after surgery compared with surgery alone for adenocarcinoma of the stomach or gastroesophageal junction. N Engl J Med 2001;345:725-30.

10. Gouzi JL, Huguier M, Fagniez PL, Launois B, Flamant Y, Lacaine F, et al. Total versus subtotal gastrectomy for adenocarcinoma of the gastric antrum. Ann Surg 1989;209:162-6.

11. Söreide JA, Van Heerden JA, Burgart LJ, Donohue JH, Sarr MG, Ilstrup DM. Surgical aspects of patients with adenocarcinoma of the stomach operated on for cure. Arch Surg 1996;131: 481-7.

12. Haugsvedt TK, Viste A, Eide GE, Soreide O, and members of the Norwegian Stomach Cancer Trial. Norwegian multicentre study of survival and prognostic factors in patients undergoing curative resection for gastric carcinoma. Br J Surg 1993;80:475-8.

13. Akoh JA, Macintyre IMC. Improving survival in gastric cancer: review of 5-year survival rates in English language publications from 1970. Br J Surg 1992;79:293-9.

14. Bonenkamp JJ, Hermans J, Sasako M, Van de Velde CJH. Extended lymph node dissection for gastric cancer. N Engl J Med 1999;340:908-14.

15. Cushieri A, Weeden S, Fielding J, Bancewicz J, Craven J, Joypaul $\mathrm{V}$, et al. Patient survival after D1 and D2 resections for gastric cancer: long-term results of the MRC randomized surgical trial. Br J Cancer 1999;79:1522-30.

16. Robertson CS, Chung SCS, Woods SDS, Griffin SM, Raimes SA, Lau JTF, et al. A prospective randomized trial comparing R1 subtotal gastrectomy with R3 total gastrectomy for antral cancer. Ann Surg 1994;220:176-82.

17. Dent DM, Madden MV, Price SK. Randomized comparison of R1 and R2 gastrectomy for gastric carcinoma. Br J Surg 1988;75:110 2.

18. Goldsmith $\mathrm{H}$, Akiyama H. A comparative study of Japanese and American gastric dimensions. Ann Surg 1979;190:690-3.

19. Logan A. The surgical treatment of carcinoma of the esophagus and cardia. J Thorac Cardiovasc Surg 1963;46:150-61.

20. Collard JM, Otte JB, Fiasse R, Laterre PF, De Kock M, Longueville $\mathrm{J}$, et al. Skeletonizing en-bloc esophagectomy for cancer. Ann Surg 2001;234:25-32.

21. Orringer MB, Marshall B, Iannettoni MD. Transhiatal esophagectomy: clinical experience and refinements. Ann Surg 1999;230: 392-403.
22. Collard JM. Exclusive radical surgery for esophageal adenocarcinoma. Cancer 2001;91:1098-104.

23. Miller RD, editor. Anesthesia, 2nd Ed. New York, Churchill Livingstone 1986;365-6.

24. Lauren P. The two histological main types of gastric carcinoma: diffuse and so-called intestinal-type carcinoma. An attempt at a histoclinical classification. Acta Pathol Microbiol Scand 1965;64: 31-44.

25. Maruyama K, Sasako M, Kinoshita T, Sano T, Katai H, Okajima K. Pancreas-preserving total gastrectomy for proximal gastric cancer. World J Surg 1995;19:532-6.

26. Collard JM, Romagnoli R. Roux-en-Y jejunal loop and bile reflux. Am J Surg 2000;179:298-303.

27. Holt CJ, Large AM. Surgical management of reflux esophagitis. Ann Surg 1961;153:555-62.

28. Bollschweiler E, Boettcher K, Hoelscher AH, Sasako M, Kinoshita T, Maruyama K, et al. Is the prognosis for Japanese and German patients with gastric cancer really different? Cancer 1993;71:2918-25.

29. Roukos DH, Lorenz M, Encke A. Evidence of survival benefit of extended (D2) lymphadenectomy in Western patients with gastric cancer based on a new concept: a prospective long-term follow-up study. Surgery 1998;123:573-8.

30. Wagner PK, Ramaswamy A, Rüschoff J, Schmitz-Moormann P, Rothmund M. Lymph node counts in the upper abdomen: anatomical basis for lymphadenectomy in gastric cancer. Br J Surg 1991;78:825-7.

31. Adachi W, Kobayashi M, Koike S, Rafique M, Nimura Y, Kuroda $\mathrm{T}$, et al. The influence of excess body weight on the surgical treatment of patients with gastric cancer. Surg Today 1995;25: 939-45.

32. Altorki N, Skinner DB. Occult cervical nodal metastasis in esophageal cancer: preliminary results of three-field lymphadenectomy. J Thorac Cardiovasc Surg 1997;113:540-4.

33. Bollschweiler E, Boettcher K, Hoelscher AH, Sasako M, Kinoshita T, Maruyama K, et al. Preoperative assessment of lymph node metastases in patients with gastric cancer: evaluation of the Maruyama computer program. Br J Surg 1992;79:15660.

34. Brady MS, Rogatko A, Dent LL, Shiu MH. Effect of splenectomy on morbidity and survival following curative gastrectomy for carcinoma. Arch Surg 1991;126:359-64.

35. Bozzetti F, Marubini E, Bonfanti G, Miceli R, Piano C, Crose N, et al. Total versus subtotal gastrectomy: surgical morbidity and mortality in a multicenter Italian randomized trial. The Italian Gastrointestinal Tumor Study Group. Ann Surg 1997;226:61320. 